\title{
A pre-biotinylated linker assembly for single-step preparation of novel biosensors
}

\author{
Brent A. Banasik ${ }^{*}$ \\ Department of Chemistry and Biochemistry, San Diego State University, San Diego, \\ CA 92182-1030, USA
}

(Received December 9, 2016; Revised January 16, 2017 ; Accepted January 27, 2017)

\begin{abstract}
A simple and efficient method for the synthesis of biotin pre-functionalized linkers via orthogonal protecting group elongation strategy is reported for a single-step preparation of new biosensor probes. The target compound 4- (4- (4- (5- ((3S, 4S, 6R)-2-oxohexahydro-1H-thieno[3,4]imidazol-4-yl) pentanamido) butanamido) butanamido) butanoic acid (5) was synthesized in five linear steps with a $40 \%$ overall yield.
\end{abstract}

Keywords: biosensor, linker, biotin, lagunamide. (C) 2017 ACG Publications. All rights reserved.

\section{Introduction}

Naturally occurring bioactive molecules are important tools for development of drug-like lead compounds. For example, lagunamide $\mathrm{A}^{1}$ is a recently discovered potential anti-cancer and antimalarial therapeutic that has spurred synthetic studies. ${ }^{2-5}$ However, the protein binding site remains unknown. Natural products have the distinct advantage of co-evolution with protein targets, usually correlated to extremely high selectivity. Determination of the molecular target(s) of novel bioactive compounds, such as lagunamide A (see Figure 1), would help to determine the mechanism of action and provide a looking glass into the convoluted cellular machinery of inhibition.
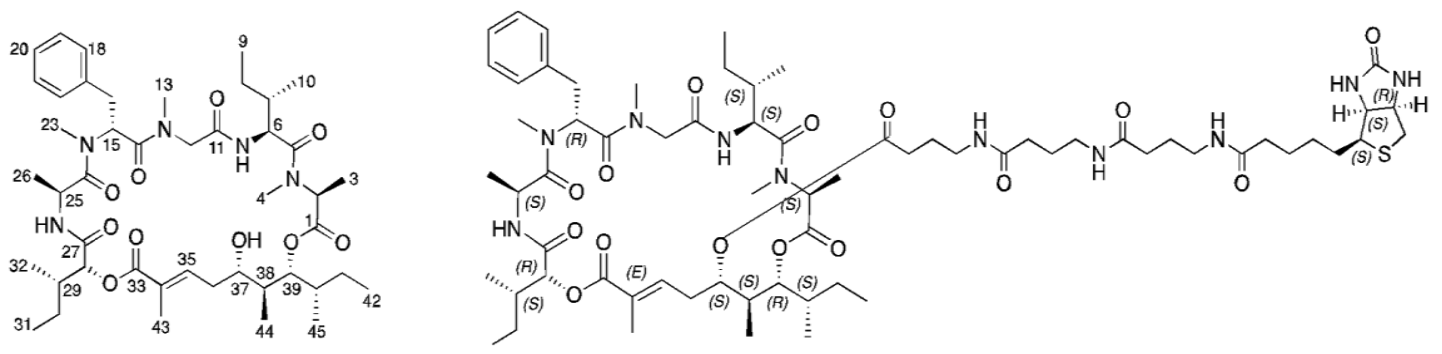

Figure 1. Structure of lagunamide A and proposed biosensor

Biotinylation is a modern technique for determination of protein targets. ${ }^{6}$ Biotin has high specific affinity for streptavidin and/or avidin. This tight binding affinity has been exploited for purification (usually affinity chromatography) or detection (usually enzyme reporters such as horseradish peroxidase or fluorescent probes). ${ }^{7}$ Convenient methods such as ELISA, electron

\footnotetext{
* Corresponding author: E-mail: brentbanasik@gmail.com; Tel: (+) 1(509)9395375; Fax: (+) 2063068838
} 
microscopy and western blots help localize these derivatives. Covalent bonding with biotin tags are unlikely to perturb the function of a molecule and lengthy linkers can probe deep into a number of enzymatic pockets in a proven method for the isolation of natural product receptors (see Figure 1). ${ }^{8}$

\section{Experimental}

IR spectra were recorded on Perkin Elmer FT-IR spectrum RXI. ${ }^{1} \mathrm{H}$ NMR spectra were recorded on a Varian 400,500 , or $600-\mathrm{MHz}$ instrument using $\mathrm{CDCl}_{3}$ or DMSO-d6 with TMS as internal standard $(\delta=0 \mathrm{ppm}) . \mathrm{CDCl}_{3}(\delta=77.00 \mathrm{ppm})$ or DMSO-d6 $(\delta=39.52 \mathrm{ppm})$ was used as internal references for ${ }^{13} \mathrm{C}(100,126$ and $151 \mathrm{MHz})$ NMR. Preparative HPLC was carried out using Shimadzu SCL-10A/SPD-10A instrument with preparative Varian pursuit 10 C8 50-G 50mm column. Mass spectra were recorded using APCI Expressions instrument. Elemental analysis was conducted by Intertek Pharmaceutical Services (USA) on a Perkin-Elmer 2400 Elemental Analyzer with NIST traceable organic standard. Analytical thin-layer chromatography was performed on Silicycle glass backed $60 \AA$ ultra pure silica gel. Flash chromatography was conducted using a Biotage Isolera one instrument with pre-packed silica gel columns (AnaLogix, Sepra Si 50) or self-packed Luknova and Biotage snap columns filled with silica gel (Sorbent Technologies, 60§, 230-400 mesh). All reactions were conducted under an argon atmosphere and in septum-capped oven-dried glassware unless otherwise specified. All solvents and reagents were purchased from Aldrich, Fisher Scientific, Combiblocks, TCI America, Chem Impex or Oakwood Scientific.

2.1. Benzyl 4-((tert-butoxycarbonyl) amino) butanoate (1): To an ice-bath cooled solution of benzyl alcohol (100 $\mu \mathrm{L}, 0.9617 \mathrm{mmol})$ and Boc-GABA-OH $(0.391 \mathrm{~g}, 1.923 \mathrm{mmol})$ in $10.0 \mathrm{~mL}$ freshly distilled DCM was added DCC $(0.496 \mathrm{~g}, 2.404 \mathrm{mmol})$ and DMAP $(0.294 \mathrm{~g}, 2.404 \mathrm{mmol})$ in one lot under argon atmosphere and the mixture was stirred for 14 hours. Completion of the reaction was confirmed by TLC and it was quenched with $15 \mathrm{ml}$ sat. $\mathrm{NH}_{4} \mathrm{Cl}$, extracted 4 x $15 \mathrm{~mL}$ DCM and the combined organics were dried over $\mathrm{MgSO}_{4}$. The mixture was filtered and concentrated to produce crude solid that was extracted with 10\% EtOAc/hexanes (Boc-GABA-OH and other impurities were generally insoluble) and purified via silica gel column chromatography (0-25\% EtOAc in hexanes gradient) to afford the title compound, monomer $1(0.273 \mathrm{~g}, 97 \%$ yield $)$ as white crystals; $\mathrm{R}_{\mathrm{f}}=0.5,25 \% \mathrm{EtOAc}$ in hexanes; ${ }^{1} \mathrm{H}$ NMR (400 MHz, Chloroform-d) $\delta 7.37-7.23$ (m, Ar-H x 5, 5H), 5.09 (s, $\left.\mathrm{CH}_{2} \mathrm{Ph}, 2 \mathrm{H}\right), 4.79$ (s, NH, $1 \mathrm{H}), 3.13$ (q, J = 6.6 Hz, NCH $2,2 \mathrm{H}$ ), 2.37 (t, J = 7.4 Hz, RCH $\mathrm{NC}_{2}, 2 \mathrm{H}$ ), 1.80 (p, J = 7.1 Hz, RCH $2 \mathrm{R}, 2 \mathrm{H}$ ), 1.41 (s, $\mathrm{OtBu}, 9 \mathrm{H}) ;{ }^{13} \mathrm{C}$ NMR $\left(101 \mathrm{MHz}, \mathrm{CDCl}_{3}\right) \delta 172.93,155.92,135.83,128.42,128.09,128.05,78.88,66.13,39.73$, 31.39, 28.30, 25.17; FTIR (neat, $\mathrm{cm}^{-1}$ ) 3320, 2933, 1731, 1708, 1683, 1540, 1365, 1163, 995, 851, 754, 699, 675 . This spectral data is identical to the previously reported literature compound. ${ }^{17}$

2.2. Benzyl 4- (4- ((tert- butoxycarbonyl) amino) butanamido) butanoate (2): To a solution of carbamate $1(0.500 \mathrm{~g}, 1.704 \mathrm{mmol})$ dissolved in $6.0 \mathrm{~mL}$ freshly distilled DCM was added $3 \mathrm{~mL}$ TFA ( $34.04 \mathrm{mmol})$ and the mixture was stirred for 80 minutes at ambient temperature under argon flow. Consumption of the starting material was confirmed via TLC. The reaction mixture was concentrated under reduced pressure and dried for $2 \mathrm{hrs}$ on HI-VAC to afford a crude (corresponding TFA salt) residue that was re-dissolved in $8 \mathrm{~mL} \mathrm{CH}_{2} \mathrm{Cl}_{2}$ and charged with Boc-GABA-OH $(0.693 \mathrm{~g}, 3.408$ mmol), HATU $(1.620 \mathrm{~g}, 4.260 \mathrm{mmol})$ and DIPEA $(1.48 \mathrm{~mL}, 8.520 \mathrm{mmol})$ successively under argon at ambient temperature and stirred sealed for $18 \mathrm{~h}$. The reaction mixture was stirred for 3 hours then charged with HOAt (1.5 equiv), resulting in similar yields. The reaction was ultimately quenched with $20 \mathrm{~mL}$ cold DI $\mathrm{H}_{2} \mathrm{O}$ and extracted with $4 \times 15 \mathrm{~mL}$ DCM. The combined organics were then washed with $20 \mathrm{~mL}$ sat. $\mathrm{NaHCO}_{3}, 20 \mathrm{~mL}$ sat. $\mathrm{NH}_{4} \mathrm{Cl}, 20 \mathrm{~mL}$ brine and dried over $\mathrm{Na}_{2} \mathrm{SO}$. The resultant combination was filtered and concentrated under reduced pressure then purified via silica gel column chromatography (50-100\% EtOAc in hexanes gradient) to afford the title compound, dimer $2(0.503 \mathrm{~g}$, $78 \%$ yield) as a pale yellow solid; $\mathrm{R}_{\mathrm{f}}=0.4,100 \%$ EtOAc; ${ }^{1} \mathrm{H}$ NMR (400 MHz, Chloroform-d) $\delta 7.43-$ 7.28 (m, Ar-H x 5, 5H), 6.37 (s, NH, 1H), $5.12\left(\mathrm{~s}, \mathrm{CH}_{2} \mathrm{Ph}, 2 \mathrm{H}\right), 4.79$ (s, NH, 1H), 3.29 (td, J = 6.9, 5.7 $\mathrm{Hz}, \mathrm{RCH}_{2} \mathrm{R}, 2 \mathrm{H}$ ), 3.14 (q, J = 6.1 Hz, RCH $2 \mathrm{R}, 2 \mathrm{H}$ ), 2.43 (t, J = $\left.7.3 \mathrm{~Hz}, \mathrm{RCH}_{2} \mathrm{R}, 2 \mathrm{H}\right), 2.18$ (t, J = 7.0 $\left.\mathrm{Hz}, \mathrm{RCH}_{2} \mathrm{R}, 2 \mathrm{H}\right), 1.86$ (p, J = 7.1 Hz, $\left.\mathrm{RCH}_{2} \mathrm{R}, 2 \mathrm{H}\right), 1.81-1.71\left(\mathrm{~m}, \mathrm{RCH}_{2} \mathrm{R}, 2 \mathrm{H}\right), 1.43$ (s, OtBu, 9H); ${ }^{13} \mathrm{C}$ NMR $\left(101 \mathrm{MHz}, \mathrm{CDCl}_{3}\right) \delta 173.24,172.82,156.61,135.84,128.59,128.29,128.22,79.47,66.41$, 
39.66, 38.97, 33.49, 31.76, 28.39, 26.41, 24.60; FTIR (neat, $\mathrm{cm}^{-1}$ ) 3422, 2984, 2942, 1709, 1653, 1540, 1366, 1253, 1229, 1167, 847; CHN calc. (\%): C (63.47), H (7.99), N (7.40); found: (\%): C (65.17), H (7.69), N (7.32).

2.3. Benzyl 2, 2-dimethyl-4, 9, 14-trioxo-3-oxa- 5, 10, 15-triazanonadecan-19-oate (3): To a solution of carbamate $2(0.350 \mathrm{~g}, 0.925 \mathrm{mmol})$ dissolved in $8.0 \mathrm{~mL}$ freshly distilled DCM was added $3 \mathrm{~mL}$ TFA (34.04 mmol) and stirred for 80 minutes at ambient temperature under argon flow. Consumption of starting material was confirmed via TLC. The reaction mixture was concentrated under reduced pressure and dried for $2 \mathrm{hrs}$ on HI-VAC to afford a crude (corresponding TFA salt) residue that was

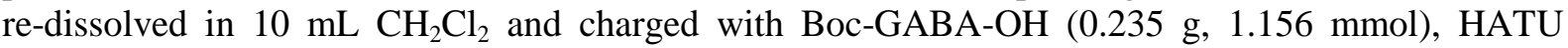
$(0.528 \mathrm{~g}, 1.388 \mathrm{mmol})$ and DIPEA $(0.645 \mathrm{~mL}, 3.700 \mathrm{mmol})$ successively under argon at ambient temperature and stirred for $1 \mathrm{~h}$. The reaction mixture was then charged with HOAt $(0.130 \mathrm{~g}, 0.462$ mmol), sealed and stirred $18 \mathrm{~h}$. The reaction was quenched with $20 \mathrm{~mL}$ cold $\mathrm{DI}_{2} \mathrm{O}$ and extracted with 4 x $15 \mathrm{~mL}$ DCM. The combined organics were then washed with $20 \mathrm{~mL}$ sat. $\mathrm{NaHCO}_{3}, 20 \mathrm{~mL}$ sat. $\mathrm{NH}_{4} \mathrm{Cl}, 20 \mathrm{~mL}$ brine and dried over $\mathrm{Na}_{2} \mathrm{SO}$. The resultant combination was filtered and concentrated under reduced pressure then purified via silica gel column chromatography (solvent mixture was 60:15:15:10 of EtOAc:ACN:MeOH: $\mathrm{H}_{2} \mathrm{O}$ isocratic gradient) to afford the title compound, trimer 3 $\left(0.255 \mathrm{~g}, 66 \%\right.$ yield) as pale yellow solid; $\mathrm{R}_{\mathrm{f}}=0.6,100 \%$ EtOAc; ${ }^{1} \mathrm{H}$ NMR $(500 \mathrm{MHz}$, Methanol-d4) $\delta$ $7.98(\mathrm{dt}, \mathrm{J}=10.3,5.7 \mathrm{~Hz}, \mathrm{NH}, 1 \mathrm{H}), 7.33$ (dd, J = 21.2, $4.4 \mathrm{~Hz}, \mathrm{Ar}-\mathrm{H}$ x 5, 5H), $5.11(\mathrm{~s}, \mathrm{NH}$ x 2, 2H), $4.83\left(\mathrm{~s}, \mathrm{CH}_{2} \mathrm{Ph}, 2 \mathrm{H}\right), 3.25-3.15\left(\mathrm{~m}, \mathrm{RCH}_{2} \mathrm{R} \times 2,4 \mathrm{H}\right), 3.07\left(\mathrm{t}, \mathrm{J}=6.9 \mathrm{~Hz}, \mathrm{RCH}_{2} \mathrm{R}, 2 \mathrm{H}\right), 2.41$ (t, J = 7.4 $\left.\mathrm{Hz}, \mathrm{RCH}_{2} \mathrm{R}, 2 \mathrm{H}\right), 2.21\left(\mathrm{t}, \mathrm{J}=7.5 \mathrm{~Hz}, \mathrm{RCH}_{2} \mathrm{R} \times 2,4 \mathrm{H}\right), 1.86-1.69\left(\mathrm{~m}, \mathrm{RCH}_{2} \mathrm{R} \times 3,6 \mathrm{H}\right), 1.43(\mathrm{~s}, \mathrm{OtBu}$, $9 \mathrm{H}) ;{ }^{13} \mathrm{C}$ NMR $\left(101 \mathrm{MHz}, \mathrm{CD}_{3} \mathrm{OD}\right) \delta 175.37,175.35,175.27,174.36,158.32,137.50,129.45,129.10$, 129.09, 79.79, 67.15, 40.72, 39.74, 39.55, 34.28, 34.26, 32.26, 28.77, 27.21, 26.66, 25.67; FTIR (neat, $\left.\mathrm{cm}^{-1}\right) 3327,2944,2486,1740,1708,1690,1652,1633,1542,1526,1452,1418,1365,1279,1254$, 1224, 1162, 1027, 1003, 852, 736, 693; CHN calc. (\%): C (62.18), H (8.05), N (9.06); found: (\%): C (61.94), H (7.89), N (9.17).

2.4. Benzyl 4-(4-(4-(5- ((3aS, 4S, 6aR)-2- oxohexahydro- 1H- thieno [3,4-d]imidazol-4-yl) pentanamido) butanamido) butanamido) butanoate (4): To a solution of carbamate trimer $3(0.050 \mathrm{~g}$, $0.1079 \mathrm{mmol}$ ) dissolved in $5.0 \mathrm{~mL}$ freshly distilled DCM was added $0.650 \mathrm{~mL}$ TFA and stirred for 90 minutes at ambient temperature under argon flow. Consumption of starting material was confirmed via TLC. The reaction mixture was concentrated under reduced pressure and dried for $2 \mathrm{hrs}$ on HI-VAC to afford a crude (corresponding TFA salt) residue that was re-dissolved in $1.75 \mathrm{~mL}$ DMF and charged with D-Biotin (0.027 g, $0.1079 \mathrm{mmol})$, HOBt $(0.020 \mathrm{~g}, 0.1295 \mathrm{mmol})$ and EDC-HCl (0.025 g, 0.1295 mmol) under argon atmosphere at ambient temperature. $0.50 \mathrm{~mL} \mathrm{Et}{ }_{3} \mathrm{~N}$ was added dropwise via cannula, and the reaction mixture was sealed and stirred for $18 \mathrm{hrs}$. To the resultant mixture was added $0.50 \mathrm{~mL}$ DCM:DMSO $(1: 1)$ that was then acidified to $\sim \mathrm{pH} 1$ with concentrated $\mathrm{HCl}$. The mixture was homogenized with the addition of $350 \mu \mathrm{L}$ DI $\mathrm{H}_{2} \mathrm{O}$. Without further workup, the reaction mixture was injected directly onto prep-HPLC (Varian C-8 $30 \times 250 \mathrm{~mm}, 5-95 \%$ ACN in $\mathrm{H}_{2} \mathrm{O}$ spiked with $0.1 \%$ formic acid, $8.5 \mathrm{~min}$ retention time) and subsequently lyophilized to afford the title compound 4 $\left(0.060 \mathrm{~g}, 80 \%\right.$ yield) as a white powder; ${ }^{1} \mathrm{H}$ NMR $(500 \mathrm{MHz}, \mathrm{DMSO}-\mathrm{d} 6) \delta 7.81(\mathrm{t}, \mathrm{J}=5.7 \mathrm{~Hz}, \mathrm{NH}$, $1 \mathrm{H}), 7.77(\mathrm{t}, \mathrm{J}=5.4 \mathrm{~Hz}, \mathrm{NH} \times 2,2 \mathrm{H}), 7.41-7.29$ (m, Ar-H x 5, 5H), $6.41(\mathrm{~s}, \mathrm{NH}, 1 \mathrm{H}), 6.35$ (s, NH, $1 \mathrm{H}), 5.09$ (s, $\left.\mathrm{CH}_{2} \mathrm{Ph}, 2 \mathrm{H}\right), 3.09\left(\mathrm{~m}, \mathrm{RCH}_{2} \mathrm{R}, 6 \mathrm{H}\right), 2.37$ (t, J = $\left.7.5 \mathrm{~Hz}, \mathrm{RCH}_{2} \mathrm{R}, 2 \mathrm{H}\right), 2.08-2.01$ (m, $\left.\mathrm{RCH}_{2} \mathrm{R}, 6 \mathrm{H}\right), 1.66\left(\mathrm{p}, \mathrm{J}=7.1 \mathrm{~Hz}, \mathrm{RCH}_{2} \mathrm{R}, 2 \mathrm{H}\right), 1.59\left(\mathrm{p}, \mathrm{J}=7.2 \mathrm{~Hz}, \mathrm{RCH}_{2} \mathrm{R}, 4 \mathrm{H}\right), 1.55-1.40(\mathrm{~m}$, $\left.\mathrm{RCH}_{2} \mathrm{R}, 2 \mathrm{H}\right), 1.31\left(\mathrm{dq}, \mathrm{J}=15.8,7.1 \mathrm{~Hz}, \mathrm{RCH}_{2} \mathrm{R}, 2 \mathrm{H}\right) ;{ }^{13} \mathrm{C}$ NMR $(101 \mathrm{MHz}, \mathrm{DMSO}) \delta 172.50,171.92$, 171.72 , 171.61, 162.68, 136.22, 128.40, 127.95, 127.88, 65.37, 61.02, 59.18, 55.38, 38.11, 37.73, $35.21,32.91,32.87,30.93,28.21,28.01,25.49,25.28,24.56$; CHN calc. (\%): C (59.06), H (7.35), N (11.88); found: (\%): C (58.98), H (7.46), N (11.63).

2.5. 4- (4- (4- (5- ((3aS, 4S, 6aR)-2-oxohexahydro-1H-thieno [3,4-d]imidazol-4-yl) pentanamido) butanamido) butanamido) butanoic acid (5): To a solution of benzyl ester 4 (0.060 g, $0.102 \mathrm{mmol})$ dissolved in dry methanol $(1 \mathrm{~mL}, 0.1 \mathrm{M})$ was added $10 \% \mathrm{Pd} / \mathrm{C}$ under inert argon atmosphere. The resulting mixture was evacuated with $\mathrm{H}_{2}(\mathrm{~g})$ and then stirred under $\mathrm{H}_{2}(\mathrm{~g})$ (1 bar) atmosphere for 12 hrs. The mixture was filtered through a celite pad and concentrated under reduced pressure to produce the title compound 5 (95\% yield, 85:15 conversion from starting material) ${ }^{1} \mathrm{H}$ NMR (500 MHz, 
Methanol-d4) $\delta 4.49$ (ddd, J = 7.9, 5.0, $0.9 \mathrm{~Hz}, 1 \mathrm{H}), 4.30$ (dd, J = 7.9, $4.5 \mathrm{~Hz}, 1 \mathrm{H}), 3.19$ (td, J = 7.0, $2.1 \mathrm{~Hz}, 8 \mathrm{H}), 2.92(\mathrm{dd}, \mathrm{J}=12.7,4.9 \mathrm{~Hz}, 1 \mathrm{H}), 2.70(\mathrm{~d}, \mathrm{~J}=12.8 \mathrm{~Hz}, 1 \mathrm{H}), 2.20(\mathrm{dtd}, \mathrm{J}=11.2,9.1,8.2,2.3$ $\mathrm{Hz}, 9 \mathrm{H}), 1.78$ (dddd, J = 15.2, 8.8, 5.3, $1.7 \mathrm{~Hz}, 6 \mathrm{H}), 1.69-1.54(\mathrm{~m}, 4 \mathrm{H}), 1.48-1.40(\mathrm{~m}, 2 \mathrm{H})$; APCI-S $m / z$ calcd for $\mathrm{C}_{22} \mathrm{H}_{36} \mathrm{~N}_{5} \mathrm{O}_{6} \mathrm{~S}$ [M-H] 498.6 , found 498.6; CHN calc. (\%): $\mathrm{C}$ (52.89), $\mathrm{H}$ (7.46), N (14.02); found: (\%): C (53.04), H (7.64), N (14.20).

\section{Results and discussion}

Sato et al. ${ }^{9}$ completed an important study to determine that Prohibitin 1 (PHB1) was the binding target protein of aurilide, ${ }^{10}$ a potent cytotoxic marine natural product that resulted in mitochondrial-induced apoptosis in cultured human cells. ${ }^{11}$ Aurilide is structurally similar and in the same macro-cyclic depsipeptide class of molecule as the more recently discovered lagunamide A. Furthermore, recent biochemical studies by Tripathi et al. ${ }^{12}$ determined that the cytotoxic effect of lagunamide A might act via mitochondrial-mediated induction of apoptosis as well. Structure-activity relationships (SAR) for aurilide showed that modification of the C35-hydroxy group (comparable to that of the C37-hydroxyl group of lagunamide A) had little to no impact on biological activity. ${ }^{13}$ It is proposed that an analogous approach to biotinylation of this hydroxyl moiety would be similarly advantageous. This strategy is applicable to a vast majority of bioactive compounds with similar hydroxyl-containing sights for biosensor derivatization.

The goal of this research was to pre-synthesize an elongated biotin linker that could then be efficiently coupled directly to a bioactive compound. Due to the laborious efforts it takes to isolate and/or synthesize such bioactive molecules, for example complex natural products such as lagunamide A, one would desire the biotin and linker moiety to be a single construct that is subsequently converged in one final step. Conversely, most biosensors are created via chemical derivitization of a bioactive molecule, usually followed by chemical manipulations that finally end in biotinylation. This research succeeded in the construction of a pre-biotinylated linker (5) that may be subsequently coupled in a single convergent step. The proposed method is more economical, straightforward, and is a valuable inclusion for the organic chemist's toolbox when compared to other commonplace strategies. Furthermore, a linker of roughly 10-20 covalent bond lengths that positioned the biotin handle well outside of the protein binding pocket is supported by the literature. ${ }^{14}$

In order to synthesize the entirety of the biotin linker prior to conjugation, an orthogonal protecting group strategy for the $C$ - and $N$-terminus of the linker was required. Thus, Steglich ${ }^{15}$ esterification of commercially available 4-(tert-Butoxycarbonylamino)butyric acid (Boc-GABA-OH) with benzyl alcohol mediated by DCC and DMAP in $\mathrm{CH}_{2} \mathrm{Cl}_{2}$ produced a completely protected monomer unit (1) in 97\% yield. Repeating units of Boc-GABA-OH made for a step-wise and uniform elongation of the linker via peptide bond fragments with advantageous protecting group strategy (see Scheme 1). When compound 1 was exposed to TFA in $\mathrm{CH}_{2} \mathrm{Cl}_{2}$, the $N$-Boc protecting group was cleaved while the $\mathrm{C}$-terminus benzyl ester remained protected. Evaporation of this mixture resulted in the crude TFA salt that was successively coupled with a second Boc-GABA-OH unit via HATU/HOAt and excess of DIPEA to produce dimer unit $\mathbf{2}$ in $78 \%$ yield over 2 steps. The identical TFA-mediated $N$-Boc removal and HATU-mediated Boc-GABA-OH coupling protocol was repeated to finalize the trimer fragment (3) comprised of the desired chain length in $66 \%$ yield over the previous two steps. A number of iterations could be continued to construct any desired chain length. Trimer 3 was $N$-Boc deprotected with TFA and evaporated to produce the crude TFA salt that was subsequently extended by D-Biotin through EDC-HCl mediated coupling to form the biotinylated trimer linker 4 scaffold in $80 \%$ yield. Inard et al. ${ }^{16}$ demonstrated that sulfur containing biotin derivatives were inert towards palladium, and thus palladium-mediated hydrogenation of benzyl ester 4 liberated the free carboxylic acid of the biotinylated linker 5 in $84 \%$ yield. Biotinylated linker 5 was equipped for direct esterification with the appropriate bioactive molecule, such as lagunamide A. 


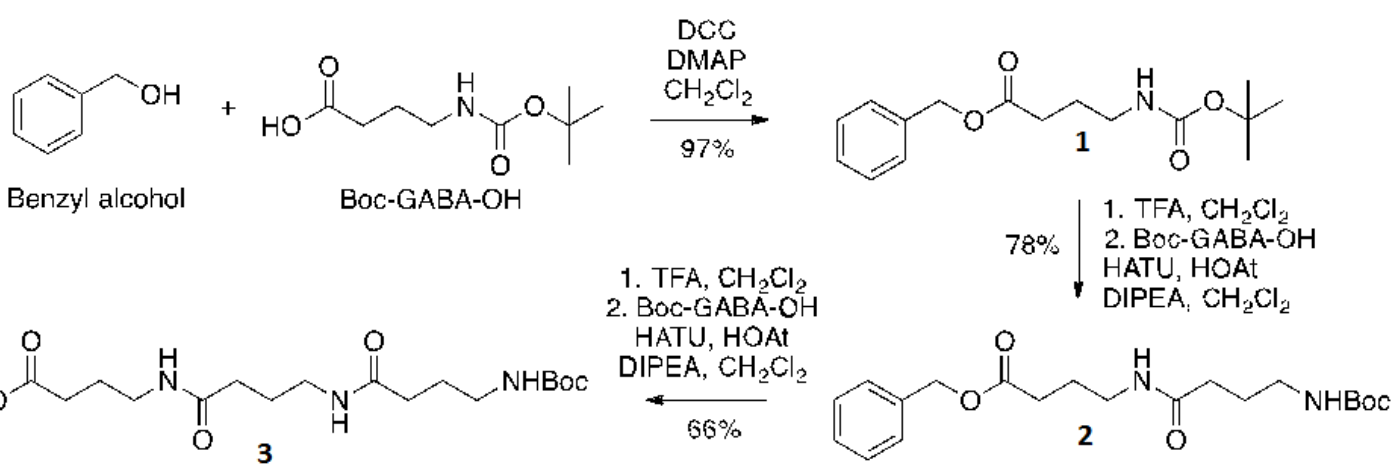

$$
\begin{array}{r}
\text { 1. } \mathrm{TFA}_{2} \mathrm{CH}_{2} \mathrm{Cl}_{2} \\
\text { 2. D-Biotin, } \mathrm{EDCC}-\mathrm{HCl} \\
\text { HOBt, } \mathrm{ET}_{3} \mathrm{~N}_{1} \mathrm{CH}_{2} \mathrm{Cl}_{2}
\end{array} \mid 80 \%
$$<smiles>CC(C)C(=O)OCCCCC(=O)NCCCC(=O)NCCCC(=O)NCCCC(=O)NCCCC(=O)OCc1ccccc1</smiles>

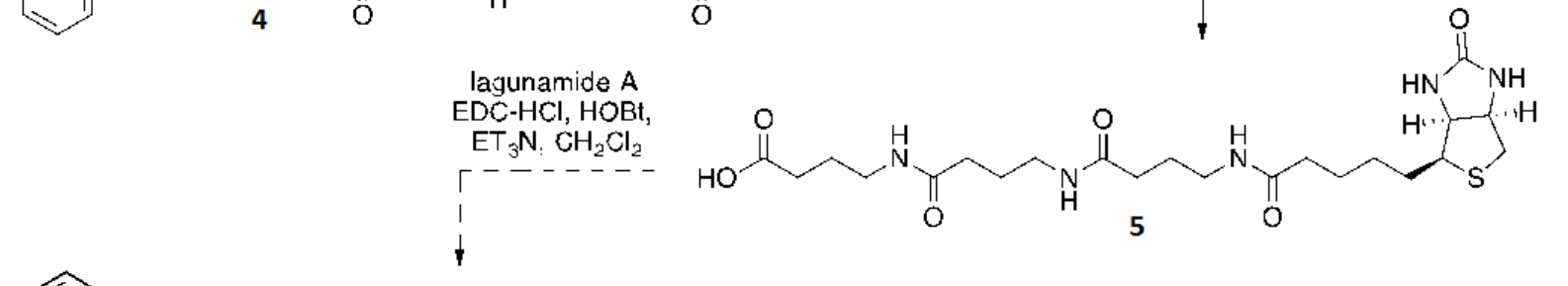

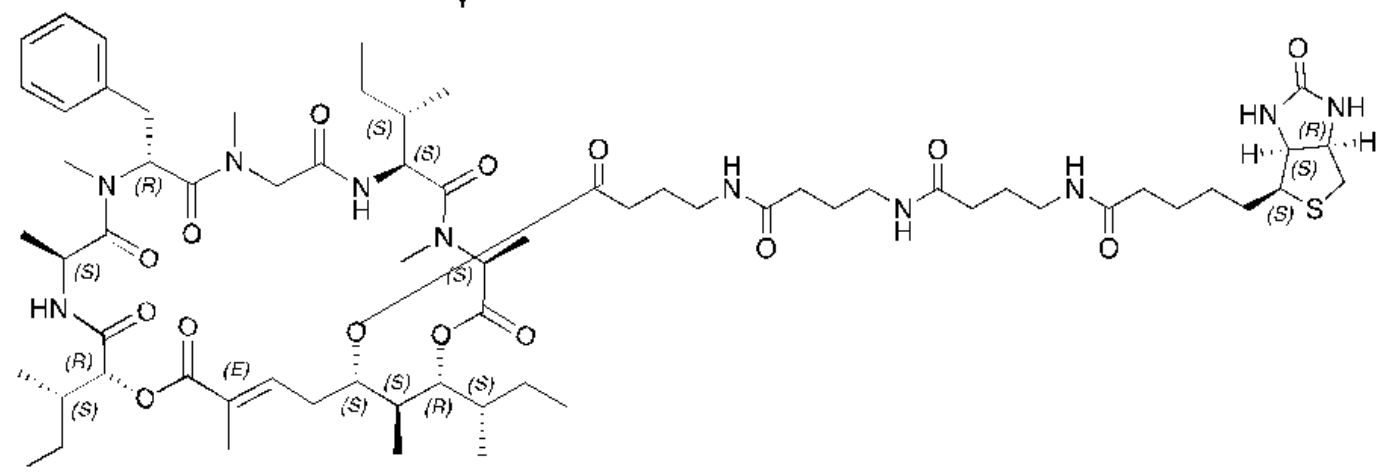

Scheme 1. Synthesis of pre-biotinylated linker towards proposed biosensor

\section{Conclusion}

Since the entire biotin-linker moiety was synthesized prior to combination, valuable steps that preserve the compound of interest are spared in constructing the corresponding biosensor. This strategy is proposed to determine the binding protein for lagunmaide A and will be reported in due course. Conceptually, this combinatory biosensor strategy would be expedient for a number of hydroxyl or amine-comprised small molecule or natural product compounds. In summary, the iterative pathway presented in this article afforded the pre-biotinylated target linker (5) in five consecutive steps with a good overall yield of $39.9 \%$.

\section{Acknowledgements}

Dr. Brent Banasik thanks Professor Bernt Mikael Bergdahl and Anna Cholewczynski for their help with this project. Financial support for this research was provided by the San Diego State University Research Fund. 


\section{References}

[1] Tripathi, A.; Puddick, J.; Prinsep, M. R.; Rottmann, M.; Tan, L. T. Lagunamides A and B: cytotoxic and antimalarial cyclodepsipeptides from the marine cyanobacterium Lyngbya majuscule. J. Nat. Prod. 2010, 73, 11, 1810-1814.

[2] Banasik, B.; Wang, L.; Kanner, A.; Bergdahl, B. M. Further insight into the asymmetric vinylogous Mukaiyama aldol reaction (VMAR); application to the synthesis of the C27-C45 segment of lagunamide A, Tetrahedron 2016, 72, 19, 2481-2490.

[3] Liu, H.-M.; Chang, C.-Y.; Lai, Y.-C.; Yang, M.-D.; Chang, C.-Y. An efficient synthesis of the C27-C45 fragment of lagunamide A, a cyclodepsipeptide with potent cytotoxic and antimalarial properties. Tetrahedron: Asymmetry 2014, 25 (2), 187-192.

[4] Huang, W.; Ren, R.-G.; Dong, H.-Q.; Wei, B.-G.; Lin, G.-Q. Diverse Synthesis of Marine Cyclic Depsipeptide Lagunamide A and Its Analogues. J. Org. Chem. 2013, 78, 21, 10747-10762.

[5] Dai, L.; Chen, B.; Lei, H.; Wang, Z.; Liu, Y.; Xu, Z.; Ye, T. Total synthesis and stereochemical revision of lagunamide A. Chem. Commun. (Camb). 2012, 48, 69, 8697-8699.

[6] Elia, G. Biotinylation reagents for the study of cell surface proteins. Proteomics 2008, 8, 19, 4012-4024.

[7] Sadaghiani, A. M.; Verhelst, S. H.; Bogyo, M. Tagging and detection strategies for activity-based proteomics. Curr. Opin. Chem. Biol. 2007, 11, 1, 20-28.

[8] Lewis, M.; Hung-Wen, L. Compr. Nat. Prod. II Chem. Biol. 10 Vol. Set, Elsevier 2010, Amsterdam, 7388.

[9] Sato, S. I.; Murata, A.; Orihara, T.; Shirakawa, T.; Suenaga, K.; Kigoshi, H.; Uesugi, Marine natural product aurilide activates the OPA1-mediated apoptosis by binding to prohibitin. M. Chem. Biol. 2011, $18,1,131-139$.

[10] Suenaga, K.; Mutou, T.; Shibata, T.; Itoh, T.; Fujita, T.; Takada, N.; Hayamizu, K.; Takagi, M.; Irifune, T.; Kigoshi, H.; Yamada, K. Aurilide, a cytotoxic depsipeptide from the sea hare Dolabella auricularia: Isolation, structure determination, synthesis, and biological activity. Tetrahedron 2004, 60, 38, 85098527.

[11] Suenaga, K.; Mutou, T.; Shibata, T.; Itoh, T.; Kigoshi, H.; Yamada, K. Isolation and stereostructure of aurilide, a novel cyclodepsipeptide from the Japanese sea hare Dolabella auricularia. Tetrahedron Lett. 1996, 37, 6771-6774.

[12] Tripathi, A.; Fang, W.; Leong, D. T.; Tan, L. T. Biochemical Studies of the Lagunamides, Potent Cytotoxic Cyclic Depsipeptides from the Marine Cyanobacterium Lyngbya majuscula. Marine Drugs 2012, 10, 5, 1126-1137.

[13] Suenaga, K.; Kajiwara, S.; Kuribayashi, S.; Handa, T.; Kigoshi, H. Synthesis and cytotoxicity of aurilide analogs. Bioorg. Med. Chem. Lett. 2008, 18, 14, 3902-3905.

[14] Xu, H.; Sabit, H.; Amidon, G. L.; Showalter, H. D. H. An improved synthesis of a fluorophosphonatepolyethylene glycol-biotin probe and its use against competitive substrates. Beilstein J. Org. Chem. 2013, 9, 89-96.

[15] Neises, B.; Steglich, W. Simple Method for the Esterificaiton of Carboxylic Acids. Angew. Chemie Int. Ed. English 1978, 17, 7, 522-524.

[16] Inard, C.; Fourcade, E.; Baron, R.; Tovar, D.; Chaisemartin, L.; Blonski, C.; Faye, J. C. Syntheses of Functionalized Biotin N-1' Derivatives: New Tools for the Control of Gene Expression with Small Molecules. Bioconjugate Chem. 2006, 17, 1030-1035.

[17] Barbayianni, E.; Fotakopoulou, I.; Schmidt, M.; Constantinou-Kokotou, V.; Bornscheuer, U.; Kokotos, G. Enzymatic Removal of Carboxyl Protecting Groups. Cleavage of the Benzyl and Methyl Moieties. $J$. Org. Chem. 2005, 70, 22, 8730-8733.

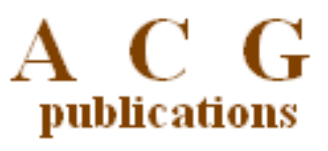

(C) 2017 ACG Publications 